\title{
Endoscopic versus laparoscopic resection of gastric gastrointestinal stromal tumors: a multicenter study
}

\author{
Wei-Jie Dai ${ }^{1, *}$, Gao Liu' ${ }^{2, *}$, Min Wang ${ }^{3, *}$, Wen-Jie Liu ${ }^{3}$, Wei Song ${ }^{4}$, Xiao-Zhong Yang ${ }^{4}$, \\ Qi-Long Wang ${ }^{5}$, Xiao-Yu Zhang ${ }^{6}$, Zhi-Ning Fan? \\ ${ }^{1}$ Institute of Digestive Endoscopy and Medical Center for Digestive Diseases, The Second Affiliated Hospital of Nanjing \\ Medical University, Nanjing, China; Department of Gastroenterology, Huai'an First People's Hospital, Nanjing Medical \\ University, Huai'an, China \\ ${ }^{2}$ Department of Gastrointestinal Surgery, Central Hospital of Enshi Autonomous Prefecture, Enshi Clinical College of Wuhan \\ University, Enshi, Hubei, China \\ ${ }^{3}$ Digestive Endoscopy Center, Jiangsu Province Hospital, The First Affiliated Hospital with Nanjing Medical University, \\ Nanjing, China \\ ${ }^{4}$ Department of Gastroenterology, Huai'an First People's Hospital, Nanjing Medical University, Huai'an, China \\ ${ }^{5}$ Department of Clinical Oncology, Huai'an First People's Hospital, Nanjing Medical University, Huai'an, China \\ ${ }^{6}$ Division of Gastrointestinal Surgery, Department of General Surgery, The Affiliated Huai'an Hospital of Xuzhou Medical \\ University and The Second People's Hospital of Huai'an, Huai'an, Jiangsu, China \\ ${ }^{7}$ Institute of Digestive Endoscopy and Medical Center for Digestive Diseases, the Second Affiliated Hospital of Nanjing \\ Medical University; Digestive Endoscopy Center, Jiangsu Province Hospital, The First Affiliated Hospital with Nanjing Medical \\ University, Nanjing, China \\ * Co-first authors \\ Correspondence to: Zhi-Ning Fan, email: fanzhining@njmu.edu.cn \\ Xiao-Yu Zhang, email: zhangxiaoyu_ey@163.com \\ Keywords: minimally invasive, resection, gastric GISTs, endoscopic, laparoscopic \\ Received: October 09, 2016 \\ Accepted: October 27, 2016 \\ Published: November 11, 2016
}

\section{ABSTRACT}

Despite endoscopic resection has been performed to treat gastric gastrointestinal stromal tumor (GISTs). However, the safety and long-term outcomes remains controversial. This study aims to compare the safety and surgical outcomes of endoscopic versus laparoscopic resection of gastric GISTs. A total of 335 patients that were pathologically confirmed with gastric GISTs (tumor size $\leq 3.5 \mathrm{~cm}$ ) were surgically treated with endoscopic resection (endoscopic group) or laparoscopic resection (laparoscopic group) in three institutions from March 1, 2011 to October 1 2014. These demographics, tumor characteristics, and outcomes were retrospectively analyzed for identification of outcomes and feasibility of endoscopic or laparoscopic resection. Of 335 patients, 262 and 73 patients underwent endoscopic and laparoscopic resection, respectively. The average tumor size was $1.33 \pm 0.78 \mathrm{~cm}$ in the endoscopic group and $1.97 \pm 0.93 \mathrm{~cm}$ in the laparoscopic group. The average operating time was $62.40 \pm 36.94 \mathrm{~min}$ in the endoscopic group and $112.81 \pm 55.69 \mathrm{~cm}$ in the laparoscopic group. Days of realimentation was $2.76 \pm 1.67$ in the endoscopic group

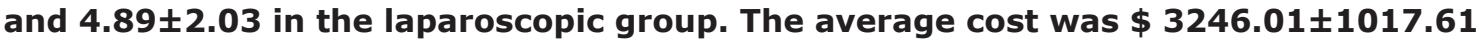
in the endoscopic group and \$ 4884.81 1339.51 in the laparoscopic group. There was no postoperative mortality. Endoscopic resection for gastric GISTs is safe and feasible in tumors $\leq 3.5 \mathrm{~cm}$. Because endoscopic resection showed good results with lower operating time, realimentation days, length of hospital stay and mean total cost, it is a minimally invasive and safe alternative approach which can achieve fast recovery and satisfactory outcomes for appropriately selected patients with gastric GISTs. 


\section{INTRODUCTION}

Gastrointestinal stromal tumors (GISTs) are the most common mesenchymal tumor in the gastrointestinal tract $[1,2]$, the most common of which are KIT or PDGFR $\alpha$ (platelet-derived growth factor receptor alpha) activation mutations [3]. As a unique disease entity, it is estimated that the annual incidence of GISTs in the world is about 7 to 19 individuals per million [4-7]. The median age at onset was about 60 years old, with biologically distinct subsets in the pediatric age group $[8,9]$. GIST is common in the stomach, followed by the intestine. However, considerable GISTs are found in the colon, esophagus and other parts of the peritoneal cavity $[10,11]$.

Normally, histological criteria show that malignancy tumors do not consistently exhibit aggressiveness. Alternatively, some tumors with typical "benign" characteristics cause metastasis. Tumor size and mitotic counts are recognized to assess prognosis. Using both indices, Fletcher and colleagues were able to classify patients with primary GISTs into four risk groups and to predict aggressive behavior. [12]. A model with a large number of patients with GISTs suggested that the anatomical location was the currently accepted risk model for local GISTs, and that the primary disease site, together with tumor size and mitotic count, provided a model of the risk of future relapse after local disease resection [10].

Localized GISTs treatment regimen including complete surgical resection. Lymph node dissection is not a standard practice, because tumor spread is usually blood-borne, rather than through the lymphatic system. If complete surgical resection with negative margins (R0 resection) is not the first attempt to achieve, can be done safely through repeated surgery, this option can be considered. Surgery is applicable to primary resectable GISTs, and is the only radical treatment. Although radical resection is performed in localized GISTs, about $40 \%$ of patients will relapse and eventually die from this disease $[13,14]$. Therefore, surgical resection should be considered in carefully selected patients with limited progressive disease that is potentially easily resectable [15-17].

Recent studies have shown that endoscopic resection is safe and viable for patients with GISTs, even in tumors up to $5 \mathrm{~cm}$ in size [18]. In theory, endoscopic resection is a simple and feasible treatment for some tumors, but the risk of early tumor recurrence with incomplete resection is a major concern for the surgeon. In contrast, laparoscopic resection is widely accepted to remove the entire tumor from a technical and oncological point of view, leading to a histologically negative margin effect. However, as far as we know, although the previous case series reported the preliminary efficacy of endoscopic resection for the treatment of gastric GISTs, there have been few studies comparing the safety and surgical outcomes of endoscopic and laparoscopic resection of gastric GISTs. Therefore, we conducted the multicenter clinical study to evaluate the advantages and disadvantages of endoscopic resection and proven laparoscopic resection in the treatment of gastric GISTs.

\section{RESULTS}

\section{Patients}

According to the patient inclusion and exclusion criteria, 335 patients were included into this study finally, with 262 patients underwent endoscopic resection (endoscopic resection group) and the other 73 patients underwent laparoscopic resection (laparoscopic resection group) (Figure 1). The clinical and pathologic characteristics of 335 patients from three hospitals are shown in Table 1. The location of the tumor included 189 cases in gastric fundus, 85 cases in gastric body, 39 cases in gastric cardia, and 14 cases in gastric antrum. The average age was $57.00 \pm 10.32$ years (range, 23 to $81 \mathrm{y}$ ) in the endoscopic resection group and 57.95 \pm 11.89 years (range, 28 to $83 \mathrm{y}$ ) in the laparoscopic resection group. The mean GIST tumor size was 1.33 $\mathrm{cm}$ in the endoscopic resection group and $1.97 \mathrm{~cm}$ in the laparoscopic resection group. Approximately 79.1\% of the patients were symptomatic and $21.0 \%$ of patients had more than five mitotic figures per fifty high power field (HPF). According to NIH risk classification, approximately $8.2 \%$ of patients had the risk from intermediate to high. There were $95.3 \%(241 / 253)$ and $97.6 \%(247 / 253)$ of the whole population CD-117 and CD-34 positive respectively. The size of GIST tumors in patients undergoing endoscopic and laparoscopic resection were in the range of 0.2 to $3.5 \mathrm{~cm}$ and 0.4 to $3.5 \mathrm{~cm}$, respectively.

\section{Perioperative outcomes}

The surgical outcomes and postoperative courses are summarized in Table 2. A total of 262 gastric GISTs patients underwent endoscopic gastrectomy. The average operative time was $62.40 \pm 36.94$ minutes. There was no postoperative mortality. Two patients due to close adhesion of the tumor to the stomach wall, endoscopic resection was not successful, the final implementation of the laparoscopic resection.

The average of operative time in laparoscopic group was $112.81 \pm 55.69$ minutes (Figure 2A). No lacrimal rupture or spillage occurred during laparoscopic surgery. Except one, all patients achieve negative surgical margins. The 52-year-old woman had a 3.5-centimeter GIST at the cardia. The patient eventually underwent open surgery and no residual tumor was found on the resected specimen. 
All patients undergoing laparoscopic surgery had no postoperative mortality. The mean length of postoperative realimentation were 2.76 and 34.89 days, respectively (Figure 2B).

In our current study, 335 consecutive hospitalized patients in three hospitals were successfully resected with a mean length of hospital stay of $5.47 \pm 2.10$ day in the endoscopic resection group and $8.21 \pm 2.64 \mathrm{~min}$ in the laparoscopic resection group (Figure 2C), and the Mean cost (\$) was limited to $3246.01 \pm 1017.61$ in the endoscopic resection group and $4884.81 \pm 1339.51$ in the laparoscopic resection group (Figure 2D).

\section{Tumor-related outcomes}

The Tumor-related outcomes are summarized in Table 2. The whole follow-up period for all 335 patients from three hospitals was finally completed in June 2016. At a mean follow-up of $32.99 \pm 14.39$ months in the endoscopic resection group and $35.32 \pm 13.28$ months in the laparoscopic resection group, only two patients $(0.72 \%)$ from the endoscopic resection group had a relapse, optimistically, these two patients did not find local recurrence. Eventually these two relapses were treated with imatinib and survived. No differences were observed in the conversion to other method rate $(2 / 252$ in the laparoscopic resection group vs $1 / 70$ in the laparoscopic resection group, $\mathrm{P}=0.522)$ and postoperative complications $(15 / 260$ in the laparoscopic resection group vs $2 / 73$ in the laparoscopic resection group, $\mathrm{P}=0.505)$ between these two groups.

\section{DISCUSSION}

GISTs are the most common mesenchymal tumor in the gastrointestinal tract, the most common of which are KIT or PDGFR $\alpha$ activation mutations [3]. Sporadic GISTs, which account for more than

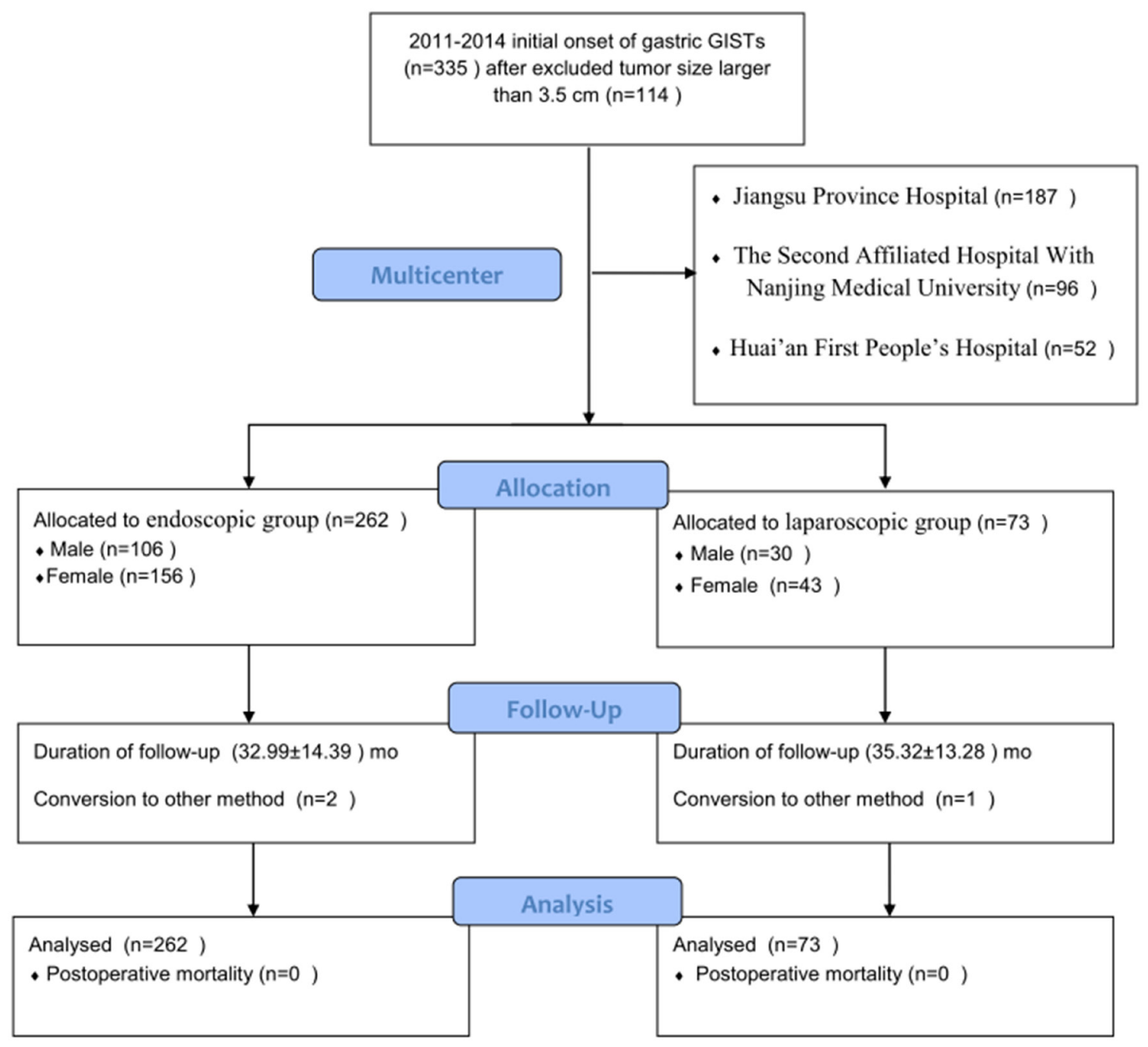

Figure 1: Flowchart of patients inclusion and exclusion. 
Table 1: Baseline characteristics of patients

\begin{tabular}{|c|c|c|c|c|}
\hline & & $\begin{array}{l}\text { Endoscopic resection } \\
\qquad(n=262)\end{array}$ & $\begin{array}{l}\text { Laparoscopic } \\
\text { resection (73) }\end{array}$ & $P$ value \\
\hline \multirow[t]{2}{*}{ Age } & Median (Range) & $58(23-81)$ & $60(28-83)$ & \\
\hline & Mean \pm SD & $57.00 \pm 10.32$ & $57.95 \pm 11.89$ & 0.540 \\
\hline \multirow[t]{2}{*}{ Gender } & Male $(n=136)$ & 106 & 30 & 1.000 \\
\hline & Female $(n=199)$ & 156 & 43 & \\
\hline \multirow[t]{4}{*}{ Symptoms } & $\begin{array}{l}\text { Abdominal pain } \\
\qquad(\mathrm{n}=193)\end{array}$ & 157 & 36 & 0.965 \\
\hline & Bleeding $(\mathrm{n}=16)$ & 4 & 12 & \\
\hline & Others $(n=56)$ & 47 & 9 & \\
\hline & No symptoms $(\mathrm{n}=70)$ & 54 & 16 & \\
\hline \multirow[t]{2}{*}{$\begin{array}{l}\text { Combined with } \\
\text { ulceration }\end{array}$} & Yes $(n=18)$ & 6 & 12 & 0.130 \\
\hline & No $(n=313)$ & 252 & 61 & \\
\hline \multirow[t]{4}{*}{ Tumor location } & Gastric fundus (189) & 154 & 35 & 0.827 \\
\hline & Gastric body (85) & 59 & 26 & \\
\hline & Gastric antrum (14) & 7 & 21 & \\
\hline & Gastric cardia (39) & 34 & 5 & \\
\hline Tumor size $(\mathrm{cm})$ & Mean \pm SD & $1.33 \pm 0.78$ & $1.97 \pm 0.93$ & 0.000 \\
\hline \multirow[t]{3}{*}{$\begin{array}{l}\text { Mitotic rate (per } 50 \\
\text { HPF) }\end{array}$} & $\leq 5 \mathrm{~cm}(83)$ & 59 & 24 & 0.255 \\
\hline & $5-10 \mathrm{~cm}(20)$ & 16 & 4 & \\
\hline & $>10 \mathrm{~cm}(2)$ & 2 & 0 & \\
\hline \multirow[t]{2}{*}{ CD34 positive } & Yes $(n=247)$ & 183 & 64 & 0.653 \\
\hline & No $(n=6)$ & 4 & 2 & \\
\hline \multirow[t]{2}{*}{ CD117 positive } & Yes $(n=241)$ & 178 & 63 & 1.000 \\
\hline & No $(n=12)$ & 9 & 3 & \\
\hline \multirow[t]{4}{*}{ NIH risk classification } & Very low risk (0) & 0 & 0 & 0.255 \\
\hline & Low risk (179) & 124 & 55 & \\
\hline & Intermediate risk (14) & 11 & 3 & \\
\hline & High risk (2) & 2 & 0 & \\
\hline
\end{tabular}

CD34, CD34 protein; CD117, CD117 protein;HPF, High-power field; NIH, National Institutes of Health; SD, standard deviation.

$95 \%$ of cases, usually arise in middle-aged to older adults, with neither gender nor race predilection. No risk factors have yet been identified. For the reason, the distinction between malignant and benign GIST has historically been difficult to elusive. The malignant potential of a GIST is unpredictable because small tumors or tumors with an appropriate number of mitotic figures can be observed metastases or recurrences too. Gastrointestinal stromal tumors are typically solitary neoplasms, mainly originating in stomach $(60 \%)$, small intestine $(30 \%)$, rectum $(5 \%)$, and esophagus $(5 \%)$. By immunohistochemistry, most GISTs are positive for DOG1 (found on GISTs) and KIT (CD117), and often also for CD34. These stains are helpful in the 
Table 2: Surgical outcomes and postoperative courses of patients

\begin{tabular}{|c|c|c|c|c|}
\hline & & $\begin{array}{c}\text { Endoscopic resection } \\
(\mathrm{n}=262)\end{array}$ & $\begin{array}{l}\text { Laparoscopic } \\
\text { resection (73) }\end{array}$ & $P$ value \\
\hline $\begin{array}{l}\text { Duration of follow-up } \\
\text { (months) }\end{array}$ & mean \pm SD $(262: 73)$ & $32.99 \pm 14.39$ & $35.32 \pm 13.28$ & 0.196 \\
\hline \multirow{2}{*}{$\begin{array}{l}\text { Conversion to other } \\
\text { method }\end{array}$} & Yes (3) & 2 & 1 & 0.522 \\
\hline & No (319) & 250 & 69 & \\
\hline \multirow[t]{3}{*}{ Resection margin } & R0 (33) & 2 & 31 & / \\
\hline & $\mathrm{R} 1(0)$ & 0 & 0 & \\
\hline & $\mathrm{R} 2(0)$ & 0 & 0 & \\
\hline \multirow[t]{6}{*}{ Complications } & None (316) & 245 & 71 & 0.505 \\
\hline & Major bleeding (2) & 2 & 0 & \\
\hline & Perforation (3) & 3 & 0 & \\
\hline & Infection (7) & 6 & 1 & \\
\hline & $\begin{array}{c}\text { Intestinal } \\
\text { obstruction }(0)\end{array}$ & 0 & 0 & \\
\hline & Other (5) & 4 & 1 & \\
\hline Operating time (min) & Mean \pm SD $(245: 72)$ & $62.40 \pm 36.94$ & $112.81 \pm 55.69$ & 0.000 \\
\hline Realimentation (days) & Mean \pm SD $(218: 56)$ & $2.76 \pm 1.67$ & $4.89 \pm 2.03$ & 0.000 \\
\hline $\begin{array}{l}\text { Length of hospital stay } \\
\text { (day) }\end{array}$ & Mean \pm SD (259:73) & $5.47 \pm 2.10$ & $8.21 \pm 2.64$ & 0.000 \\
\hline Mean cost $(\$)$ & Mean \pm SD $(262: 73)$ & $3246.01 \pm 1017.61$ & $4884.81 \pm 1339.51$ & 0.000 \\
\hline Mean cost $(Y)$ & Mean \pm SD $(262: 73)$ & $21960.53 \pm 6884.53$ & $33027.37 \pm 9062.31$ & \\
\hline \multirow[t]{2}{*}{ Postoperative mortality } & Yes $(0)$ & 0 & 0 & l \\
\hline & No (281) & 219 & 62 & \\
\hline \multirow[t]{2}{*}{ Recurrence } & Yes (2) & 2 & 0 & 1.000 \\
\hline & No (279) & 217 & 62 & \\
\hline
\end{tabular}

$\mathrm{SD}$, standard deviation.

differential diagnosis of morphologically similar intraabdominal lesions. [13] Complete surgical excision is the treatment of choice and the only known curative therapy for primary localized, resectable GIST. However, approximately half of patients undergoing macroscopically complete surgical resection will experience disease recurrence within the following 5 years. [43] For decades pathologists have attempted to identify macroscopic or microscopic markers that could predict the risk of recurrence of localized GIST after surgery. The only features that have proved to be predictive of GIST behavior are tumor size and mitotic rate.
Some studies have shown that a safety margin of 1 to $2 \mathrm{~cm}$ includes a possible 5 -mm micro-extension in GISTs leads to complete resection $[19,20]$ However, the controversy in the surgical margin is still under investigation. Because each GIST is now considered potentially malignant, all stromal tumors are recommended for surgical resection. Our results show that only 2 $(0.72 \%)$ of the patients with tumors $<3.5 \mathrm{~cm}$ have a high mitotic index consistent, further validate the above points. Compared with open surgery, laparoscopic resection of gastric stromal tumors has been shown to be feasible, safe, and has an excellent incidence of complications, $[21,22]$ endoscopic resection, a new technique for the 
treatment of gastric GIST, represents a less invasive alternative to surgical procedures. Endoscopic resection can be safely performed by experienced endoscopic specialists, and overall resection is preferable to local resection to accurately assess the adequacy of treatment. However, endoscopic resection of the gastric GISTs still has some problems. For example, the incidence of intraoperative bleeding, perforation and resection failure is high $[23,24]$. In this study, the incidence of perforation and resection failure were $1.15 \%$ and $0.91 \%$ in endoscopic resection patients. Second, few studies have reported that endoscopic resection is suitable for GIST. Stromal tumors accurate preoperative diagnosis is mandatory for optimal therapy. Because the accuracy of endoscopic ultrasound needle biopsy has not yet been determined, so now is not considered a practical diagnostic method. Therefore, the safety of endoscopic resection in GISTs should be carefully studied. Our results suggest that when the tumor neointima grows well on the edge and there is a potential muscle layer under endoscopic ultrasonography, endoscopic resection can be used to the GISTs (less than $3.5 \mathrm{~cm}$ ) and select the cases with high surgical risk, morbidity, or the need to preserve organ function. However, its applicability to oncology principles should be further evaluated by more patients.

Prognostic factors of recurrence have been investigated for R0 or R1 surgical patients, GIST tumor size, mitosis and tumor location is considered to be significant and independent prognostic factor [10, 12, 25]. In addition, rare tumor rupture has recently been identified as a prognostic factor $[5,26]$. Macroinvasion may also be beneficial for patient risk stratification [26].

The recently reported findings have demonstrated a detailed survival rate of patients who underwent resection of locally excised gastric GIST. Although our study has shown satisfactory results in patients undergoing laparoscopic surgery for gastric GISTs, the retrospective analysis and the lack of comparative data on open or laparoscopic surgery as limitations of this clinical retrospective study. Thus, multi-center, prospective and comparative studies should be evaluated in endoscopic versus laparoscopic surgery for the different sizes of gastric stromal tumors.

In summary, laparoscopic resection may be a preferred alternative to small-size $(<3.5 \mathrm{~cm})$ tumors for locally resectable gastric GISTs. In addition, endoscopic resection showed more excellent results with lower operating time, realimentation days, length of hospital stay and mean total cost. Endoscopic resection is a minimally invasive treatment, and has the advantages of rapid recovery and satisfactory efficacy for gastric GISTs patients. Endoscopic resection could be considered for the treatment of gastric GISTs less than $3.5 \mathrm{~cm}$ in diameter. Further studies should be evaluated by more patients.
A

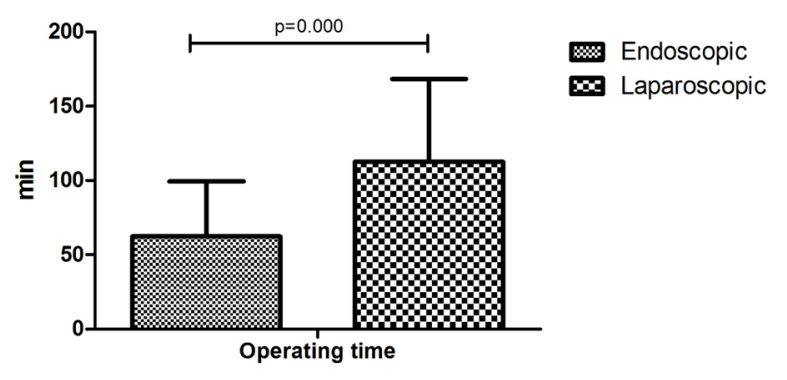

C

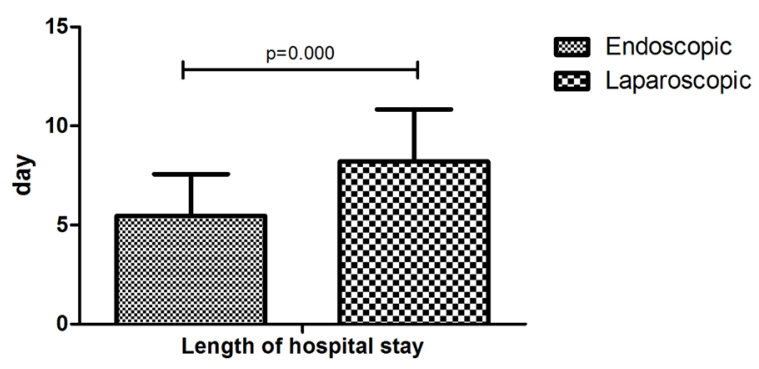

B

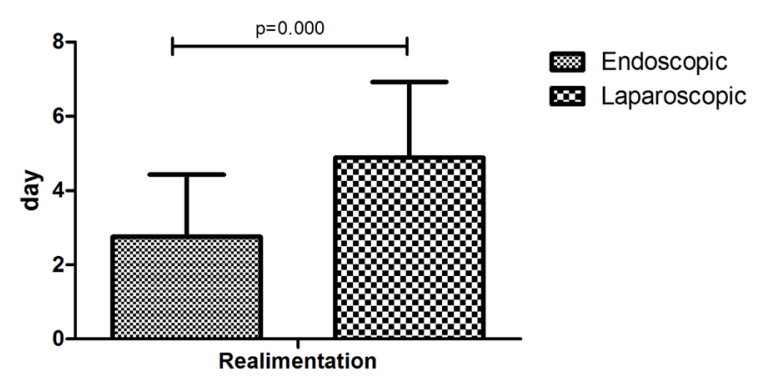

D

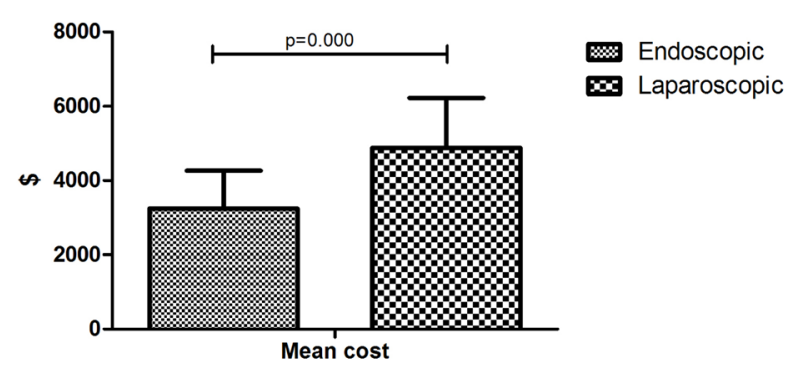

Figure 2: A. Operating time ( $\mathrm{min}$ ) of patients by treatment options; B. Realimentation (days) of patients by treatment options; C. Length of hospital stay (days) of patients by treatment options; D. Mean cost (\$) of patients by treatment options. 


\section{MATERIALS AND METHODS}

\section{Patients}

In this study, the data were retrospectively and prospectively collected from patients who underwent endoscopic resection (endoscopic group) or laparoscopic resection (laparoscopic group) for gastric GISTs between March 1, 2011 and October 12014 in three hospitals (Jiangsu Province Hospital, Nanjing Medical University, Jiangsu, China; The Second Affiliated Hospital With Nanjing Medical University, Jiangsu, China; Huai'an First People's Hospital, Nanjing Medical University, Jiangsu, China). This study was conducted according to institutional ethics guidelines and was approved by the institutional review board in each institution. All procedures followed were in accordance with the ethical standards of the responsible committee on human experimentation and with the Helsinki Declaration of 1964 and later versions. Informed consent was obtained from all patients for being included in the study. Written informed consents were obtained from the patients for the publication of this report and any accompanying medical records.

The following patients were included in this study: (1) patients with tumor diameter no larger than $3.5 \mathrm{~cm}$ based on preoperative endoscopic ultrasonography (EUS) and/or abdominal computerized tomography (CT) examination; (2) patients who had not taken aspirin, warfarin, or other nonsteroidal anti-inflammatory drug for at least 1 week before the endoscopic resection; (3) patients who had normal complete blood count, prothrombin time, and thrombin time; "normal" means within the normal range; (4) patients with no other malignant tumors; (5) and patients who were pathologically diagnosed as having gastric GISTs preoperatively or postoperatively. Patients who refused surgical intervention were excluded. The surgical approaches were decided according to the tumor growth pattern, EUS findings, or patients' preference.

\section{Pathological diagnosis}

When histopathology revealed spindle, epithelioid, or mixed features by hematoxylin and eosin (H\&E) staining, and when immunohistochemical analysis showed KIT (CD117) and/or CD34 positivity, patients were diagnosed with GIST. The histopathological features, cell shape, and number of mitoses per $50 \mathrm{HPF}$ were obtained by examination of H\&E-stained specimens. Mitoses were counted at the highest power, and mean values were used for the analysis after counting the fields twice. For patients who lacked pathological data, including immunohistochemistry, we histologically re-examined their surgical materials by the pathologist, when their paraffin blocks were available and usable.
Patients were classified using the NIHC and AFIPC $[5,10]$. Since the NIH consensus criteria do not specify how to classify tumors with exactly 5 mitoses per $50 \mathrm{HPF}$ or tumors that are exactly 2,5 , or $10 \mathrm{~cm}$ in size, we defined mitosis and tumor size in the NIH consensus criteria as follows: $<5 / 50$ or $\geq 5 / 50 \mathrm{HPF}$, and $\leq 10 / 50$ or $>10 / 50 \mathrm{HPF}$ for mitosis, and $<2$ or $\geq 2 \mathrm{~cm}, \leq 5$ or $>5 \mathrm{~cm}$, and $\leq 10$ or $>10 \mathrm{~cm}$ for tumor size. In brief, for the NIHC criteria, we stratified patients into 4 risk groups: very low risk, low risk, intermediate risk, and high risk. Two pathologists who were blinded to the data reviewed all the specimens; if their initial diagnoses differed, the pathologists would reassess the specimens and discuss their findings to reach the consensus. Characteristics of the patients such as their age and gender, those of the operation including the operating time and conversion rate, the size and location of the tumor as well as postoperative complications were recorded.

\section{Surgical management}

For each patient, treatments were allocated based upon patient will and clinicopathological characteristics, which were assessed by the Expert Team in each Hospital. These teams comprised gastroenterologists, endoscopists and general surgeons. Written informed consent was obtained from each patient prior to surgical treatment.

All patients received general anesthesia. The surgical procedures included endoscopic resection (endoscopic group) and laparoscopic resection (laparoscopic group). Endoscopic resection was mainly chosen for patients with tumors originating from the muscularis propria or tumors with intragastric type and clear boundaries to adjacent tissues and organs. The patients were sedated using intravenous midazolam, with monitoring of the heart rate, blood pressure, and oxygen saturations. Conscious sedation was maintained with additional injections of midazolam during the procedure. Grasping forceps, an insulated-tip knife (KD-610L, Olympus Optical Co. Ltd), a hook knife (KD-620LR, Olympus Optical Co. Ltd.), and a polypectomy snare tip were used for dissection of the tumor complete with normal mucosa from surrounding tissue after injection of saline, including epinephrine (1:100000) and diluted indigo carmine dye. An electrocautery snare was used for coagulation in some cases. Complete endoscopic resection of gastric GISTs is regarded as the absence of any remnant of tumor visible on endoscopy after tumor resection. All endoscopic resections were performed by skilled endoscopic specialists and surgeons. Laparoscopic surgery was performed in reverse Trendelenburg position. After insertion of a subumbilical trocar by a Veress approach, the other 3 ports were added under laparoscopic observation. All procedures were performed by three experienced surgeons in their own hospitals. The surgeon stood between or to the left of the patient's legs. The first assistant was to the right or the 
left of the patient's body, and the gastroscope was placed at the left of the patient's head. Four ports (three $5 \mathrm{~mm}$ in diameter and one $12 \mathrm{~mm}$ in diameter) were inserted into the upper left and upper right quadrants at $10 \mathrm{~mm}$. A $30^{\circ}$ laparoscope was introduced through a subumbilical port following carbon dioxide $\left(\mathrm{CO}_{2}\right)$ insufflations of up to $13 \mathrm{mmHg}$. A drainage tube was placed in the abdominal cavity in case intraoperative complications occurred. All patients were routinely managed using a standardized postoperative protocol.

\section{Patients follow-up}

Patients were scheduled for follow-up with abdominal CT scanning and/or esophagogastroduodenoscopy according to risk classification, every 6 months during the first year of follow-up and every 12 months thereafter in those with very low or low risk of tumor recurrence, and every 3 months in the first year of follow-up and every 6 months thereafter in intermediate-risk patients and every 3 months in high-risk patients. Follow-up was completed by either chart review or telephone interview in August 12016.

\section{Statistical analysis}

Statistical analyses were performed using SPSS 21.0 (SPSS Inc., Chicago, IL, USA). The age of the patients, together with the operating time, tumor size and the length of hospital stay were presented as mean \pm standard deviation (SD). The categorical data were presented as number and percentage. The different characteristics were compared between the groups using a Chi-square test or Fisher's exact test for categorical variables and using a Student's t-test for continuous variables. $\mathrm{P}<0.05$ was considered as statistically significant.

\section{CONFLICTS OF INTEREST}

The authors declare that they have no conflicts of interest.

\section{REFERENCES}

1. Zhuang C, Wang M, Qiu WQ, Xu J, Shen ZY, Cao H. [Clinicopathological features and management of gastrointestinal stromal tumors complicated with synchronous other alimentary malignant tumor]. Zhonghua Wei Chang Wai Ke Za Zhi. 2013; 16:234-238.

2. Joensuu H, Fletcher C, Dimitrijevic S, Silberman S, Roberts $\mathrm{P}$, Demetri G. Management of malignant gastrointestinal stromal tumours. LANCET ONCOL. 2002; 3:655-664.

3. Hirota S, Isozaki K, Moriyama Y, Hashimoto K, Nishida T, Ishiguro S, Kawano K, Hanada M, Kurata A, Takeda M, Muhammad TG, Matsuzawa Y, Kanakura Y, Shinomura Y, Kitamura Y. Gain-of-function mutations of c-kit in human gastrointestinal stromal tumors. SCIENCE. 1998; 279:577-580.

4. Nilsson B, Bumming $\mathrm{P}$, Meis-Kindblom JM, Oden A, Dortok A, Gustavsson B, Sablinska K, Kindblom LG. Gastrointestinal stromal tumors: the incidence, prevalence, clinical course, and prognostication in the preimatinib mesylate era - a population-based study in western Sweden. CANCER-AM CANCER SOC. 2005; 103:821-829.

5. Joensuu H. Risk stratification of patients diagnosed with gastrointestinal stromal tumor. HUM PATHOL. 2008; 39:1411-1419.

6. Steigen SE, Eide TJ. Trends in incidence and survival of mesenchymal neoplasm of the digestive tract within a defined population of northern Norway. APMIS. 2006; 114:192-200.

7. Rossi S, Miceli R, Messerini L, Bearzi I, Mazzoleni G, Capella C, Arrigoni G, Sonzogni A, Sidoni A, Toffolatti L, Laurino L, Mariani L, Vinaccia V, Gnocchi C, Gronchi A, Casali PG, et al. Natural history of imatinib-naive GISTs: a retrospective analysis of 929 cases with long-term follow-up and development of a survival nomogram based on mitotic index and size as continuous variables. AM J SURG PATHOL. 2011; 35:1646-1656.

8. Janeway KA, Liegl B, Harlow A, Le C, Perez-Atayde A, Kozakewich H, Corless CL, Heinrich MC, Fletcher JA. Pediatric KIT wild-type and platelet-derived growth factor receptor alpha-wild-type gastrointestinal stromal tumors share KIT activation but not mechanisms of genetic progression with adult gastrointestinal stromal tumors. CANCER RES. 2007; 67:9084-9088.

9. Agaram NP, Laquaglia MP, Ustun B, Guo T, Wong GC, Socci ND, Maki RG, DeMatteo RP, Besmer P, Antonescu CR. Molecular characterization of pediatric gastrointestinal stromal tumors. CLIN CANCER RES. 2008; 14:3204-3215.

10. Miettinen M, Lasota J. Gastrointestinal stromal tumors: pathology and prognosis at different sites. SEMIN DIAGN PATHOL. 2006; 23:70-83.

11. Nishida T, Hirota S, Yanagisawa A, Sugino Y, Minami M, Yamamura Y, Otani Y, Shimada Y, Takahashi F, Kubota T. Clinical practice guidelines for gastrointestinal stromal tumor (GIST) in Japan: English version. INT J CLIN ONCOL. 2008; 13:416-430.

12. Fletcher CD, Berman JJ, Corless C, Gorstein F, Lasota J, Longley BJ, Miettinen M, O'Leary TJ, Remotti H, Rubin BP, Shmookler B, Sobin LH, Weiss SW. Diagnosis of gastrointestinal stromal tumors: A consensus approach. HUM PATHOL. 2002; 33:459-465.

13. DeMatteo RP, Lewis JJ, Leung D, Mudan SS, Woodruff JM, Brennan MF. Two hundred gastrointestinal stromal tumors: recurrence patterns and prognostic factors for survival. ANN SURG. 2000; 231:51-58.

14. von Mehren M, Benjamin RS, Bui MM, Casper ES, Conrad ER, DeLaney TF, Ganjoo KN, George S, Gonzalez R, Heslin MJ, Kane JR, Mayerson J, McGarry SV, Meyer C, 
O'Donnell RJ, Paz B, et al. Soft tissue sarcoma, version 2.2012: featured updates to the NCCN guidelines. J Natl Compr Canc Netw. 2012; 10:951-960.

15. Raut CP, Posner M, Desai J, Morgan JA, George S, Zahrieh D, Fletcher CD, Demetri GD, Bertagnolli MM. Surgical management of advanced gastrointestinal stromal tumors after treatment with targeted systemic therapy using kinase inhibitors. J CLIN ONCOL. 2006; 24:2325-2331.

16. Sym SJ, Ryu MH, Lee JL, Chang HM, Kim TW, Kim HC, Kim KH, Yook JH, Kim BS, Kang YK. Surgical intervention following imatinib treatment in patients with advanced gastrointestinal stromal tumors (GISTs). J SURG ONCOL. 2008; 98:27-33.

17. Raut CP, Wang Q, Manola J, Morgan JA, George S, Wagner AJ, Butrynski JE, Fletcher CD, Demetri GD, Bertagnolli MM. Cytoreductive surgery in patients with metastatic gastrointestinal stromal tumor treated with sunitinib malate. ANN SURG ONCOL. 2010; 17:407-415.

18. Jeong IH, Kim JH, Lee SR, Kim JH, Hwang JC, Shin SJ, Lee KM, Hur H, Han SU. Minimally invasive treatment of gastric gastrointestinal stromal tumors: laparoscopic and endoscopic approach. Surg Laparosc Endosc Percutan Tech. 2012; 22:244-250.

19. Dressler JA, Palazzo F, Berger AC, Stake S, Chaudhary A, Chojnacki KA, Rosato EL, Pucci MJ. Long-term functional outcomes of laparoscopic resection for gastric gastrointestinal stromal tumors. SURG ENDOSC. 2016; 30:1592-1598.

20. Mikami T, Nemoto Y, Numata Y, Hana K, Nakada N, Ichinoe M, Murakumo Y, Okayasu I. Small gastrointestinal stromal tumor in the stomach: identification of precursor for clinical gastrointestinal stromal tumor using c-kit and alpha-smooth muscle actin expression. HUM PATHOL. 2013; 44:2628-2635.

21. De Vogelaere K, Hoorens A, Haentjens P, Delvaux G. Laparoscopic versus open resection of gastrointestinal stromal tumors of the stomach. SURG ENDOSC. 2013; 27:1546-1554.

22. Matthews BD, Walsh RM, Kercher KW, Sing RF, Pratt BL, Answini GA, Heniford BT. Laparoscopic vs open resection of gastric stromal tumors. SURG ENDOSC. 2002; 16:803-807.

23. Dinis-Ribeiro M, Pimentel-Nunes P, Afonso M, Costa N, Lopes C, Moreira-Dias L. A European case series of endoscopic submucosal dissection for gastric superficial lesions. GASTROINTEST ENDOSC. 2009; 69:350-355.

24. Park YS, Park SW, Kim TI, Song SY, Choi EH, Chung JB, Kang JK. Endoscopic enucleation of upper-GI submucosal tumors by using an insulated-tip electrosurgical knife. GASTROINTEST ENDOSC. 2004; 59:409-415.

25. Washington K. 7th edition of the AJCC cancer staging manual: stomach. ANN SURG ONCOL. 2010; 17:3077-3079.

26. Takahashi T, Nakajima K, Nishitani A, Souma Y, Hirota S, Sawa Y, Nishida T. An enhanced risk-group stratification system for more practical prognostication of clinically malignant gastrointestinal stromal tumors. INT J CLIN ONCOL. 2007; 12:369-374. 